\title{
EMBODIMENT IN COGNITIVE LINGUISTIC: FROM EXPERIENTIALISM TO COMPUTATIONAL NEUROSCIENCE
}

\section{(Corporeidade em linguística cognitiva: do experiencialismo à neurociência computacional)}

\author{
Heloísa Pedroso de Moraes Feltes \\ (Universidade de Caxias do Sul - BRAZIL)
}

\begin{abstract}
The aim of this paper is to reflect on the character of embodiment in the framework of Cognitive Linguistics based on Lakoff, collaborators and interlocutors. Initially I characterize the embodied mind, via cognitive experientialism. In these terms, the theory shapes how human beings build and process knowledge structures which regulate their individual and collective lives. Next, the Neural Theory of Language in which embodiment is rebuilt from a five level paradigm, where structured connectionism carries on the very burden of computational description and explanation is discussed. From these assumption, classical problems about computational implementations for models of natural language functioning as reductionist-physicalist approaches, I then conclude by assuming that embodiment, as an investigation phenomenon, shouldn't be formulated in terms of levels, being treated as interfaces instead, at such manner that: (a) the epistemological commitments should be synchronically sustained in all interfaces of the investigation paradigm; (b) the conventional computational level should be taken as one of the problems which has to be treated in the structured connectionism plan; (c) the strategic reduction levels paradigm and the results obtained from it might imply a kind of modularization of the program of research itself; e (d) the modules would be interdependent only as a result of the reductionist proposal. As a result, I assume that it is possible to do Cognitive Linguistics without adhering to structured connectionism, or to neurocomputacional simulation, as long as one would operate with interfaces constructions between domains of investigation and not with a reductionist features paradigm treated in terms of "levels".
\end{abstract}

Key-words: embodiment; cognitive linguistics; neural theory of language.

Resumo: Este artigo é uma reflexão sobre o caráter da corporeidade no quadro da Lingü̈́stica Cognitiva associada a Lakoff, colaboradores e interlocutores. Inicia-se com a caracterização de mente corpórea, via experiencialismo cognitivo. A teoria, nesses termos, modela como os seres humanos constroem e processam estruturas de conbecimento que regulam sua vida individual e coletiva. Em seguida, discute-se a Teoria Neural da Linguagem, em que a corporeidade é reconstruida a partir de um paradigma de cinco níveis, em que o conexionismo estruturado carrega o peso da descrição e explanação computacional. Em vista disso, retomam-se

D.E.L.T.A., 26:especial, 2010 (503-533) 
problemas clássicos sobre implementações computacionais para modelos de funcionamento da linguagem humana, em abordagens reducionistas-fisicalistas. Como conclusão, defende-se que a corporificaçãa, como fenômeno de investigação, que se problematize sua formulação em termos de niveis, tratando-a, em vez disso, como interfaces, de modo que: (a) os compromissos epistemológicos deveriam ser sincronicamente mantidos nas interfaces; (b) em função de (a), o nível das computações deveria ser tomado como um dos problemas a serem tratados no plano do conexionismo estruturado; (c) a estratégia de um paradigma em níveis de redução e os resultados obtidos a partir dela implicam uma espécie de modularização do programa de pesquisa; e (d) esses módulos seriam interdependentes apenas em vista dos níveis criados para atender a determinados objetivos. Como resultado, assume-se que épossivel fazer-se Lingüística Cognitiva sem aderir ao conexionismo estruturado ou à simulação neurocomputacional, desde que se operaria com construções de interfaces entre domínios de investigação, e não com um paradigma em niveis, com traços reducionistas.

Palavras-chave: corporificação; linguística cognitiva; teoria neural da linguagem.

\section{INTRODUCTION}

When embodiment is brought up in Cognitive Linguistics, the main idea is to distinguish between the body as a "physiological entity" and the body as a "phenomenological entity". Embodiment, at the start of Cognitive Linguistics, has to do with the phenomenological body as I (we) experience it, independently of knowing how the physiological processes work in such a body. In other words, research is not focused on the body itself, but towards a being who is embodied within the world in which cultural factors rule the way this world is experienced and starts to have meaning for us. Embodiment, when understood in such a way, is also part of our cognitive unconscious because the various processes by means of which we conceptualize the world are in a "lower" level of our conscious activity.

The embodiment issue becomes a complex one when Lakoff's, colaborators' and closer interlocutors' ongoing global research program is examined. That is why the purpose of this paper originally presented at the round table on Embodiment and Metaphor is to reflect on the character of embodiment in the overall framework of Cognitive Linguistics inaugurated by Lakoff. Section 2 characterizes in general terms the concept of the embodied mind via cognitive experientialism in which embodiment has strictly a phenomenological character ${ }^{1}$. Section 3 discusses the Neural

1. In the present paper the term phenomenological must always be understood in Merleau-Ponty's ([1945], 1999) terms. It relates to the body as it is experienced. The phenomenal field is not an 
Theory of Language in which embodiment is repositioned and treated in five levels: Cognitive Science and Cognitive Linguistics, Neurally Reductive Conventional Computational Models, Structured Connectionist Model, Computer Neuroscience and Neuroscience. Section 3.1 discusses briefly the computational simulation in the Neural Theory of Language. Section 3.2 raises some of the problematic issues arising as a result of the paradigm's ontological commitments. Once the issue of the computational level required by this paradigm is considered, section 4 discusses traditional questions in the scope of Cognitive Science over computational implementations of models which are concerned with the effective functioning of human language. Particularly, it is discussed reductionist-physicalist approaches in the philosophy of mind. Finally, in the conclusion, I defend that the understanding and treatment of embodiment, in the inter-levels relation, is not yet sufficiently clear under a metatheoretical point of view. In spite of the new design of the investigation program, the overall idea of the discussion suggests that is possible to develop research within the limits of Level 1 in which Cognitive Linguistics pre-Neural Theory of Language is situated.

\section{Cognitive EXPERIENTIALISM AND EMBODIED REALITY}

Cognitive experientialism grounded in experimental psychology studies by Eleanor Rosch, Berlin \& Kay, Kay \& Mc Daniel, in aspects of Gestalt Theory, in Wittgenstein's philosophy and in Putnam's Internal Realism has, since Lakoff s (1977, 1982, 1987, 1988), Lakoff \& Johnson's (1980), Johnson's (1988), initial writings, become the epistemological basis in the field of Cognitive Semantics, and in Cognitive Linguistics ${ }^{2}$ as a whole. Therefore, since its foundation Cognitive Linguistics has been

\footnotetext{
"interior world", and the phenomenon is not a "state of conscience" or a "psychic fact" completely constructed by a perceiving subject. According to the philosopher: "The most important acquisition of phenomenology has no doubt been the uniting of extreme subjectivism to extreme objectivism in its notion of the world or of rationality. Rationality is exactly proportional to the experiences in which it reveals itself. There is rationality, that is: the perspectives confront one another, an apparent sense. [.... The phenomenological world is not the pure being, but the sense the results in the intersection of my experiences, and in the intersection of my experiences with those of the other, by the overlapping of these two; the phenomenological world is therefore inseparable from subjectivity and from the intersubjectivity which form its unity by means of the retaking of my past experiences into my present experiences, from the other's experiences in mine." (Marleau-Ponty 1999: 18) [The original quotation was in Portuguese]

2. See Feltes (2007) for an overview of historical-theoretical background.
} 
geared towards a convergence with and shown high interest in discussions and results from research carried out in fields of study such as Cognitive Psychology, Philosophy of Mind, Philosophy of Language, Neuroscience and Artificial Intelligence.

Lakoff (1982: 154), favoring an "experimental point of view", says that " $[\ldots]$ the major issue presented a theory of language is to know how language ought to fit into a general theory of cognition, human development, and social interaction." According to the author:

After a generation of research in which it was implicitly assumed that language could be described on its own terms, it has become more interesting to ask how much of the structure of language is determined by the fact that people have bodies with perceptual mechanisms and memory and processing capabilities and limitations, by the fact that people have to try to make sense of the world using limited resources, and by the fact that people live in social groups and have to try to communicate with each other. It seems to me a great deal of the structure of language is determined by such factors. (Lakoff 1982: 155)

On the other hand, mental experience embodiment results from the idea that

Such factors - anatomical, physiological, perceptual, neurological, genetic determine and constrain the range of our abilities and the quality of our mental experience. Most obviously, they define a range of possible speech sounds and the parameters for their characterization. They likewise define and structure conceptual space (the base for meaning and grammar). What we posit for language ought to be plausible from the biological perspective. (Langacker 1999: 15)

Departing from Cartesian dualist reasoning structures, the thesis is that the mind is embodied in the sense that human reason itself results from "concrete" lower-level bodily schemas which are meaningful and emerge as a consequence of our sensory-motor experiences. Such experiences give rise to image schemas of kynesthesic-motor nature which structure higher levels of our conceptual system: abstract concepts, different ways of reasoning, inferences, etc. Emotions and various different experiences labeled as "quail" by philosophers are also included in such conceptual system.

In these terms, Lakoff \& Johnson (1999) characterize human reason as follows: 
Reason is not disembodied, as the tradition has largely held, but arises from the nature of our brains, bodies, and bodily experience. This is not just the innocuous and obvious claim that we need a body to reason; rather, it is the striking claim that the very structure of reason itself comes from the details of our embodiment. The same neural and cognitive mechanisms that allow us to perceive and move around also create our conceptual systems and modes of reason. Thus, to understand reason we must understand the details of our visual system, our motor system, and the general mechanisms of neural binding. In summary, reason is not, in any way, a transcendent feature of the universe or of disembodied mind. Instead, it is shaped crucially by the peculiarities of our human bodies, by the remarkable details of the neural structure of our brains, and by the specifics of our everyday functioning in the world. [...]

Reason is not "universal" in the transcendent sense [...]. It is universal, however, in that it is a capacity shared universally by all human beings. What allow it to be shared are the commonalities that exist in the way our minds are embodied.

Reason is not completely conscious, but mostly unconscious.

Reason is not purely literal, but largely metaphorical and imaginative.

Reason is not dispassionate, but emotionally engaged. (Lakoff \& Johnson 1999: 4)

A secondary thesis is that the mind in a ubiquitous way makes use of imaginative mechanisms, such as metaphor and metonymy. In this way, our conceptual system via embodiment, including our own linguistic knowledge (grammatical), becomes structured from schemas of sensory-motor nature. Conceptual Metaphor Theory has developed in this background: primary metaphors, complex metaphors; correlational metaphors; resemblance metaphors, metonymies and the metonymy-metaphor continuum. Highly abstract concepts such as the ones related to morality, are studied from the perspective of categories of unidirectional or bidirectional conceptual metaphor categories, or blending theory.

\section{Neural Theory of Language: the struCtured CONNeCtionism}

For the last ten years, Lakoff and his collaborators have argued the metaphor is a neural mechanism. This neural mechanism used in sensory-motor activities creates forms of abstract reasoning and, therefore, establishes the potential and the limitations in which this abstract reasoning operates. In other words, the term "embodiment" is associated with the concept that our brains take in as inputs, sensory-motor experiences which are afforded by the type of bodies we have and from the ways we actuate 
in a historical and culturally situated physical world. From the foregoing, it can be said that context and cultural factors play a fundamental role in the emergence of the phenomenological body, language and cognition.

The Neural Theory of Language (NTL) research group based in Berkeley ${ }^{3}$ and of which George Lakoff is a member, has an interest in answering questions such as:

(a) How can brains work as minds?

(b) How can the neural intricate structures that human brains have provide a complete series of human concepts?

(c) What kind of structures do the types of concepts characterize? And why?

(d) How do the neural systems in human brains learn specific types of concepts and the language which expresses them?

The NTL website summarizes the project purposes into one general question, four research questions and three "tools" used to answer them. The guiding question is: "How does the brain compute the mind?". The specific questions are: (a) "How do the specific neural structures of the human brain shape the nature of thought and language?"; (b) "How are language and thought related to other neural systems, including perception, motor control, and social cognition?"; (c) "What are the computational properties of neural systems?"; and (d) "What are the applications of neural computing?". The "tools" are:

(1) Converging constraints: We draw on ideas from computer science, linguistics, cognitive science, and psychology.

(2) Cognitive modeling: We build models of cognitive phenomena, including simulations of language and learning.

(3) Reductionist requirement: Theories and models must have biologically plausible interpretations.

What the NTL researchers name as "tools" has a diverse meaning. In (1), the "converging constraints" represent the commitment with the converging results in the referred areas; in (2) the "cognitive modeling" is to be understood as the method that, empirically, makes the interdisciplinary relations possible; and (3) is a meta-theoretical/ ontological demand: the theories and models about mind/thought and language must be reducible

3. Neural Theory of Language (NTL), developed in the International Computer Science Institute (ICSI). 
to biological theories and methods, so that "interpretation" means "translation" in reductionist terms.

The group works with the structured connectionism proposed by Jerome Feldman, whose purpose is "to provide neural models of embodied cognition, especially the acquisition and use of language and thought as described in cognitive linguistics" (Lakoff \& Johnson 1999: 569). Thus, the structured connectionism "becomes the central link between language and thought, on the one hand, and the highly specific neural structures of the brain, on the other, since it can simultaneously model neural computation and the forms of computation required by language and thought." (Lakoff \& Johnson 1999: 569).

As Lakoff \& Johnson (1999) state, the NTL shares a common paradigm with all current trends in Cognitive Science, which is described in three layers:

The highest level: Cognitive

The intermediate level: Neural-computational

The lowest level: Neural-biological

The operations in the neural system described in the neural-biological level are modeled at the neural-computational level and as a result of the neural system modeling, it is shown through neural computational methods - and this is a gigantic step - "how the cognitive effects at the top level are achieved by neurobiology at the bottom level." (Lakoff \& Johnson 1999: 570).

The NTL has a strategy to make this transition more manageable. It creates a five-level paradigm:

Level 1: Cognitive Science and Cognitive Linguistics

Level 2: Neurally Reducible Conventional Computational Models

Level 3: Structured Connectionist Model

Level 4: Computational Neuroscience

Level 5: Neuroscience

How do these levels relate to one another? Let us start with the lowest levels ( 4 and 5). Computational neuroscience models model the brain as 
if it were made of groups of electric circuits (circuitry), with axons and dendrites seen as connections with activations and inhibitions of positive and negative numerical values. This is explained as follows:

Neural cell bodies are conceptualized as 'units' that can do basic numerical computations (adding, multiplying, etc.). Synapses are seen as points of contact between connections and units. Chemical actions at the synapses determines a synaptic weight" - a multiplicative factor. Learning is modeled as change in these synaptic weights. Neural 'firing' is modeled in terms of a threshold,' (sic), a number indicating the amount of charge required for the 'neural unit' to fire. The computations are all numerical. (Lakoff \& Johnson 1999: 571)

The second level operates due to the neural system properties. It has parallel processing, distributed control, ability to react fast and efficiently to change contexts etc. These conventional computational models are used just when it is known how to map them directly to the structured connectionist neural models. According to the authors:

Such conventional computational mechanisms are only used when it is know how to map them directly to structured connectionist neural models, and it is common for novel forms of conventional-style models to be constructed along these guidelines. Thus, only neutrally reducible computational models are used in the modeling (Lakoff \& Johnson 1999: 571)

That means, according to Lakoff \& Johnson (1999: 571), that "[v] ery few conventional computational systems satisfy all the requirements". However, there is no ontological relevance to be attributed to the conventional computational levels. The authors are clear about this:

It is there purely for convenience, to make the job of neural modeling easier. The neural computations attributed to the brain are characterized on Level 3, the structured connectionist level. These must be equivalent to the neural computations carried out by the more complex brain circuitry on Level 4, which more directly models the details of the physical brain (Lakoff \& Johnson 1999: 571-572).

As the structured connectionist model searches for such a complex simplification in the brain circuits, so it happens to the connection between level 4 and 3: the structured connectionism creates a simplified representation of this circuit, "in which equivalent computations are carried out by neural circuitry of minimal complexity" (Lakoff \& Johnson 1999: 571). This way, in my point of view, the structured connectionism ends up with the 
computational description and explanation in its own level (as the most intermediate level).

The global scenario is as it follows: level 5 down to level 1 are covered by neuroscience research, which provides hardcore evidence that links cognitive science and linguistics to the effective brain. The connections between Levels 1, 2, 3, 4 and 5 are concerned with computation and attempt to answer the how-questions, as to the way in which nerve cells via neural computations may characterize thought and language. The direct connection of level 1 to level 5 is an attempt to answer the where-questions: where in the brain do the computations take place?

Based on the neural approach perspective, embodiment refers to structures and neural processes that are activated and co-activated, so that it generates patterns of cognitive and behavioral actions. Along these lines, Feldman (2006: 49), states that " $(t)$ he macroscopic properties of mind and language arise (...) from the microscopic properties of neurons, and the mechanisms of neural signaling, neural adaptation, and neural growth." (p. 49). The mental connections are active neural connections. Thus, there is reason to believe that ideas, concepts and similar things are represented by neural activity. The author says that it is not possible to say for sure which exact circuit is involved, but it is enough to agree "that some stable connection pattern is associated with each word, concept, schema, and so on." (Feldman 2006: 91).

As to embodied language, Feldman (2006: 9) explains:

Because language is complex, linguists have traditionally broken its study artificially into "levels" or "modules" given names such as phonetics, phonology, morphology, syntax, the lexicon, semantics, discourse, and pragmatics. Most linguists specialize in the study of just one level or at the border between two adjacent subfields. Such focused studies have told a great deal about language and are still the norm.

However, real language is embodied, integrated, and multimodal. When your doctor asks you to lift your leg, your understanding involves a rich interaction among many neural systems. There is systematic structure to how all these components fit together to constitute language. The rule or patterns of language are called constructions, and these integrate different facets of language - for example, phonology, pragmatics, semantics, and syntax. A request construction might specify a grammatical form, an intonation pattern, pragmatic constraints, and the intended meaning. When your doctor asks you to lift your leg, all of these features are involved.

Feldman's neural model for the embodied language is connectionist, but it embodies a computational level. His thesis is that 
A description of any mental ability [...] must be reducible to the connectionist level and thus to the brain [...]. But the connectionist level is still messy, so we also need a computational level, providing a fairly traditional way to describing structures in terms of features-value pairs. (Feldman 2006: 288)

The author states that neural computation has become a standard way of thinking about how the brain operates. However, since "neurons are just cells, tiny biological entities that are alive and function by means of chemistry". "Why can we say that?" (Feldman 2006:16), "Why could it be said that "neurons process information and perform computation?" (Feldman 2006:16). He considers these questions from two interrelated issues, as follows: (a) if neural computation connects our experiences of hearing and speaking to our experiences related to perception, movement and imagination; (b) so, we need to know more about neural computation to understand the language.

\subsection{NeUrocomputacional Simulation}

According to Feldman, in first place, there are reasons "for postulating that language understanding is best seen as simulation." (2006: 215). Among these reasons, there are experiments which register images of brain activities in linguistic tasks. For example, consider a "word generation" task. The person is asked to name an activity which would be appropriate to a printed word, such as ride (activity) to bike (printed word). The images obtained show areas with high blood flow, which indicate high neural activity. It is also possible to verify that the areas activated "include prefrontal brain regions associated with planning and also parts of the brain that are used in carrying out the actions themselves." (Feldman 2006: 217). This way, the simulation model would be highly embodied in its empirical basis.

Probabilistic reasoning takes on a central role in a simulation model. ${ }^{4}$ The simulation is conducted by a computer program which "makes possible the study of a complex dynamic system by designing an information processing model of the system and running it as a program on a digital

4. 'Simulation', along Feldman's exposition (2006), is quite often used as a synonym of 'imagination' (to simulate $=$ to imagine). 
computer." (Feldman 2006: 30). When it is about modeling the brain, the task is extremely more complex: "Any direct modeling of neural circuits is complicated by the fact that a neuron can be affected by the thousands of other neurons that are connected to them." (Feldman 2006: 32). His purpose is to

[...] establish a style of modeling at the right level of detail for studying thought and language. We suggest this is both feasible and informative, and such a modeling style reveals a great deal of crucial detail about how the brain is able to embody language and other mental function. (Feldman 2006: 32)

The group of sentences below can illustrate the relation between simulation and inferences in the embodied neural approach (cf. Feldman 2006: 214). There is always a choice of perspective in the simulation: (a) from an agent; (b) from an experiencer; and (c) from a watcher. According to Feldman, the grammatical system "analyses the utterance in context and produces a linked collection of frames and schemas that specify what actions took place and which actors and other entities were involved" (Feldman 2006: 219). So, considering sentences such as the following, different perspectives can be adopted.

\section{(13.a) Harry walked to the café,}

One can, in each case, adopt the perspective of an outside observer (someone outside the café), and, inferentially, not be certain whether Harry really went or not into the cafe. In such a case, the café is simulated as a destination, fulfilling the role of the image scheme. SOURCE-PATHGOAL. When this sentence is heard, Harry can be simulated as walking, and, according to Feldman, "the results of the simulated execution are the inferences that result from the input sentence"/ "provides only part of the information for the simulation." (Feldman 2006: 219, 220).

\section{(13.b) Harry came into the café,}

The inside perspective from a watcher inside the place can, in this case, be adopted. Inferentially, the speaker is inside the cafe and saw when the agent came in. The place (café) takes up the role of the CONTAINER schema. 
(13.c) Harry stumbled into the café,

In this case, the perspective from a person who is inside the place, but, who is not necessarily only an observer is adopted. Feldman states "[b]y offering more information on Harry, [... $]$ invite[s] us to simulate the scene from Harry's perspective; we can imagine being Harry in this situation." (Feldman 2006: 214, 215). "Stumbled" suggests that Harry has some physical problem and " $[. .$.$] we need to learn or imagine whether Harry was$ sick, or drunk, or just tripped on some obstacle.” (Feldman 2006: 218).

(13.e) Harry escorted Josh into the café.

This situation may be simulated from Josh's perspective, and, inferentially, if Josh were Jane, maybe the imposing intonation of Harry's action would disappear.

One of the basic ideas from the computer simulation is that the " $[\ldots]$ background, context, and goals of the understander determine exactly what will be simulated and at what level of detail" (Feldman 2006: 220)

\subsection{Multiple LEVELS FOR EMBODiment}

Lakoff \& Johnson (1999) admit that embodiment, in the proposed paradigm, has different levels, and each of them need explanation. The proposed levels are:

(1) Neural embodiment

(2) Conscious experience phenomenological embodiment.

(3) Cognitive unconscious embodiment.

The reasons for the existence of these levels are:

Embodied truth requires us to give up the illusion that there exists a unique correct description of any situation. Because of the multiple levels of our embodiment, there is no one level at which one can express all the truths we can know about a given subject matter. But even if there is no one correct description, there can still be many correct descriptions, depending on our embodied understandings at different levels or from different perspectives. Each different understanding of a situation provides a commitment to what is real about that situation.

Each such reality commitment is a version of a commitment to truth. (Lakoff \& Johnson 1999: 109) 
However, among these levels, it is not clear which effectively the ontological commitments are. Compare the three sentences with underlined passages below:

(i) When, for example, we say that a construct of a cognitive science such as "verb" or "concept" or "image schema" is real, we mean the same thing as any scientist means: It is an ontological commitment of a scientific theory and therefore can be used to make predictions and can function in explanation. It is like the physicist's ontological commitment to "energy" and "charge" as being real. Neither can be directly observed, but both play a crucial role in explanation and prediction. The same can be said of neural computation, conceptual metaphor, prototypes, morphemes, verbs, and so on. (Lakoff \& Johnson 1999:109)

(ii) No ontological relevance is ascribed to the level of conventional computations. It is there purely for convenience, to make the job of neural modeling easier. The neural computations attributed to the brain are characterized on Level 3, the structured connectionist level. These must be equivalent to the neural computations carried out by the more complex brain circuitry on level 4, which more directly models the details of the physical (Lakoff \& Johnson 1999: $571,572)$.

Not attributing ontological relevance to the conventional computational levels (ii) is not only a strategy, but a demand in reductionism. That means, the model needs to abandon this sort of computation some time, whose inconvenience is situated in the bases of Cognitive Linguistics and in the empirical background which supports the rejection of a digital (classic) computational mind. The structured connectionism does not have tools that are able to eliminate this level. As Feldman (2006: 14) states, "[c] urrently we have nothing close to a complete neural computational model of thought and language".

Another explanation is attempted by the authors. Now it refers to arrangements respecting metaphorical entities:

(iii) Most cognitive scientists have a theoretical commitment to the reality of such things as phonemes, verbs, and concepts, not in the same sense as a commitment to the reality of chairs and rocks, but nonetheless a commitment at some appropriate level of understanding. Similarly, cognitive neuroscientists engaged in neural computation have a theoretical commitment to the reality of neural gates, synaptic weights, thresholds, and mathematical operations "performed by neurons" (addition, subtraction, multiplication, differentiation, integration, vector addition, and so on). Of course, the numbers used in such calculations are not literally there in the cell bodies. The mathematics used in the computations is part of a critically important metaphor. This is the central metaphor of computational neuroscience, a metaphor 
that appears to [... ] accurately characterize how biological neural networks function. In computational neuroscience, where the metaphor is taken for granted, synaptic weights (which are numbers) are seen as properties of neural networks, and learning is understood as the changing of synaptic weights, which in the technical models is the changing of numbers. Embodied realism makes sense of commitments to the scientific reality of such metaphorical entities as the numbers in a computational model referred to a "synaptic weights. (Felman 2006: 111).

The proposal synthesized from statements (i) and (iii) with the observation in (ii) becomes a problem when one tries to understand the global functioning of a theoretical paradigm. Theoretical commitments implicate ontological commitments, but they are not synonyms. Understanding Embodied Realism and, specially, the concept of embodiment in an inter or trans-disciplinary way demands this type of thinking from researchers. From such, researchers would be ready to judge what - up to which point or level - and how to explore the potential in the paradigm, establishing for itself a set of theoretical commitments and, eventually, ontological and methodological ones as well, in different application areas.

The explanation in (III) is based on analogies. Metaphor is a cognitive phenomena, but determining its ontological status, in the context of this paradigm, is not simple. If the neural computations are ontologically relevant, it is crucial to investigate in what way computations of analogical nature, probabilistic, are responsible for the dynamic generation of metaphors, making the outcome of these operations become an epiphenomenon. Once again, the difference between commitments with theoretical entities and ontological commitments needs to be clarified.

\section{CoMputational PROCESSES AND PSYCHOLOGICAL REDUCTIONISM: BACK TO OLD PHILOSOPHIC QUESTIONS ${ }^{5}$}

Cognitive Science and, specifically, Artificial Inteligence, postulate the existence of representational mental states (Fodor \& Pylyshyn 1988). The theoretical models differ about the postulation of the existence or non existence of symbolic representational states - those which have

5. Back to this discussion, but with many alterations and corrections, Feltes (1998) and chapter 1 by Feltes (2007). 
syntactic structure and compositional semantics. The classic model of mental architecture defends the existence of such symbolic states, which constitute a language of thought that, as it was mentioned before, makes the computational operations possible, as a medium. The connectionist model ${ }^{6}$ develops systems that can show intelligent behavior without stocking, retaining or operating with structured symbolic expressions.

Fodor \& Phylyshyn (1988) state that there are two kinds of operations the connectionist models make possible: learning and thinking. If the model focuses on learning, "there will be processes that determine the weight of the connections among its units as a function of the character of its training" (Fodor \& Phylyshyn 1988: 30). Learning would be basically a kind of statistic modeling. The authors remind the principle of the "old associationism", which deals with

The strength of association between 'Ideas' is a function of the frequency with which they are paired 'in experience' and the Learning Theoretic principle that the strength of a stimulus-response connection is a function of the frequency with which the response is rewarded in the presence of the stimulus. But though Connectionists, like other Associationists, are committed to learning processes that model statistical properties of inputs and outputs, the simple mechanism based on co-occurrence statistics that were the hallmarks of old-fashioned Associationism have been augmented in ["new"] Connectionist models by a number of technical advices. (Fodor \& Phylyshyn 1988: 31)

If the model, on the other hand, focuses on thinking, the connectionist model can operate in a way that the inputs for a specific function are specifications of connectivity (for an analogical machine); of loads along the

6. McLaughlin (1993) affirms that the word connectionism, used by Feldman and Ballard to refer to software family for researches in Cognitive Science, has been being used to cover all kinds of software that develop distributed or parallel processing models of cognition. Such software has historic roots in Hume's empiricist Associationist tradition. Connectionism seems to establish how an alternative to the classic conception of cognition, to the conception of the thought language, as it has been shown so far, a computational conception of the mind based on the manipulation of symbols governed by rules - "a metaphor of the digital computer" - the connectionists see the computation as a "brain metaphor", conceiving neurologically distributed systems. Despite at some level considering the existence of parts, they are not considered constituents. McLaughlin (as other researchers in the area as well) believes that the cognitive architecture should try to include a classic architecture which was implemented by classic symbolic processes, these, by connectionist processes. He states: "connectionism would be quantum mechanics and classicism, just chemistry. If there were a Nobel Prize in psychology, a proposal about how a brain connectionist network implements a classic architecture would certainly win". (1993: 184) 
connections; of values of a variety of idiosyncratic standards of nodules; of a pattern of excitement on the node inputs. Thus, the function output is a specification of a pattern of excitation over the output nodes; intuitively, the machine chooses the output pattern that is most highly associated to its input" (Fodor \& Phylyshyn 1988: 32). They believe that:

Much of the mathematical sophistication of Connectionist theorizing has been devoted to devising analog solutions to this problem of finding a 'most highly associated' output corresponding to an arbitrary input. [...][II]n Connectionist models, the selection of an output corresponding to a given input is a function of properties of the paths that connect them (including the weights, the states of intermediate units, etc.) And the weights, in turn, are a function of the statistical properties of events in the environment [...]. But the syntactic/semantic structure of the representation of an input is not presumed to be a factor in determining the selection of a corresponding output since [...] syntactic/semantic structure is not defined for the sorts of representations that Connectionist models acknowledge.

According to these authors, the disagreements between the classic model defenders and the connectionists have to do with the nature of the mental representations themselves. For the classic approach defenders, but not for the connectionists, the mental representations have a combinatorial constituent nature, as well as a combinatorial semantics. They also disagree about the nature of the mental processes, because, for the classics, but not for the connectionists, the mental processes are sensitive to these combinatorial structures.

According to Smolensky (1988), for example, the compositionality principle of the classic architectures is false because the contents are not invariant inside the context. Fodor \& Pylyshyn (1988) have an opposite idea about this. For them, as a language is systematic, the lexical item must contribute approximately in the same way to each expression in which it occurs. The authors suspect that the degree of variation induced by contextual lexical meaning is frequently over estimated because other kinds of sensibility to the context are wrongly interpreted like a violation of the compositionality principle. Cognitive systematicity is, according to Fodor \& Pylyshyn, a good reason to postulate the structure of the combinations in the mental representations, exactly like it occurs in productivity: noncompositional systems are not productive.

For the classic architecture defenders, systematization depends crucially on the idea of conceiving mental representation as language, in other words, 
mental representation has syntax and combinatorial semantics. (Fodor \& McLaughlin 1990). The "classic" isomorphism defenders state that usually when an S complete formula expresses the proposition $\mathrm{P}$, the $\mathrm{S}$ elements express (or refer to) the P elements. It does not matter what metaphysical suppositions about the proposition elements might be; whether individuals themselves or individual concepts, what really matters is that, in this model, there is an internal structure in the mental representations, which is the one of the proposition they express. That means, the mental processes are sensitive to the structure in the mental representations. According to the classic approach, systematization is nomologically necessary, for it would express a psychological law which could understand all the "systematic" minds.

Furthermore, if the connectionists accept the systematization, it will leave them only two options: (a) or the systematization must be explained without the compositionality, (b) or they must accept the compositionality. The connectionists answer towards this varies. Some questioned the notion of compositionality, establishing degrees of compositionality (weak or strong), as in Smolensky (1988), or typologies/ styles of compositionality (relational or functional), as in Van Gelder (1990).

Thus, one of the problems pertaining to the five levels paradigm of Language Neural Theory has to do with questions related to productivity and systematization that classic models manage to cover through the syntactic and semantic compositionality. Since the (formal) constituent, compositionality is not defended by Cognitive Linguistics, as a general rule for the cognitive-linguistic structure, having in mind its commitment with empirical data about the effective functioning of human language, this commitment and problem go through the five proposed levels.

Another context for discussion is about the naturalistic project: a philosophical macro-project which aims to show that mental states are part of the natural world. According to Fodor (who is a representative of the classic models), if it is not possible to offer a naturalistic approach to mental representation, there is no possibility for a scientific psychology. That is what Warfield \& Stich (1994) generally called naturalistic restriction in Cognitive Science. The naturalistic project is linked to causation (mentalintentional), in many regards and this takes one back to the questions of compositionality. 
In general terms, the idea of mental naturalism is the one that the mind is part of the natural world, but it is not ontologically primitive. That does not necessarily mean that a naturalistic theory is a physicalistic theory. What is expected is that its vocabulary is totally non-mental: "The root assumption of naturalism [...] is that mental states have essences that are expressible in non-mental language." (Tye 1992: 422).

This is Fodor's idea about the naturalistic project for the mental content. Fodor (1990: 32) states:

The worry about representations is above all that the semantic (and/or the intentional) will prove permanently recalcitrant to integration in the natural order; for example, that the semantic/intentional properties of things will fail to supervene upon their physical properties. What is required to relieve the worry is therefore, at a minimum, the framing of naturalistic conditions for representation.

This position must be understood according to the philosophical context. Fodor (1994a), in a paradigmatic reductive way, establishes two categories of mind traditional philosophies: (i) the dualists - the mind is a non-physical substance; and (ii) the materialists - the mind is not different from the physical substance. ${ }^{7}$

The philosophical question of naturalization can be expressed in the following way, according to Fodor \& Lepore (1994: 143): "To put it in the standard philosophical jargon, semantic properties must supervene on non-semantic properties." The semantic properties cannot be reductively semantic. Or as the authors affirm: "we don't care whether semantic properties supervene on something that is physical just as long they supervene on something other than themselves."

This discussion takes place in a scientific-philosophical context, in general in the Reduction Theory. Besides intending to be a theory to connect the sciences, it aims ultimately to unify science - topic which is not under

7. In the twenties and thirties, logical positivism defends the thesis that science must be founded on some sort of inter-subjective, observational and empirical check. At this time, for example, behaviorism determines that the checking condition would be satisfied by the observation of behavior, which becomes the locus of the mind-body relation. In this perspective, the behavior, as response patterns to physical stimuli, is the only observational data in psychology. Between the fifties and seventies, the Identity Theory is developed. Here, every mental state/event is identified as neurophysiologic states/events. Every state/event is numerically equal to a neurophysiologic state/event, this way, denying the existence of mental entities. (Lycan 1990; Place 1990; Watson 1990). 
discussion here. The discussion about the Reduction Theory here is done by Jerry A. Fodor's arguments and it can be explained by the attention given to the character of the structures and mental processes in the computational level. It is exactly the computational level of the Language Neural Theory that we want to highlight at the end of this section, in which it is suggested to be included in some type of reductionist project.

Fodor (1981: 127) deals with Reduction Theory from what it is called "A typical thesis of positivistic philosophy of science" and all true theories in the special sciences should be reduced to physical theories "in the long run". It is understood that this a type of reductionism - here understood as the classic reductionism discussed in Psychology - a doctrine of empirical intention, in the sense that all the events that fit into the laws of any science are, indeed, physical events and they must be submitted to physical laws. In other words, in this type of reductionism, the theories of special sciences must be reduced to physical theories. This reducibility is taken as restriction about the acceptability of the special science theories. Fodor goes against this restriction arguing that it does not play any relevant role in the practical validation of theories. The author characterizes reductionism through the following procedure: ${ }^{8}(1)$ There is a formula $S_{1} x \rightarrow S_{2} y$, as a law of a special science; (2) $\mathrm{S}_{1}$ e $\mathrm{S}_{2}$ are attributes of a special science; (3) the formulas (a) $S_{1} x \Leftrightarrow P_{1} x$, (b) $S_{2} y \Leftrightarrow P_{2} y$ and (c) $P_{1} x \rightarrow P_{2} y$ are necessary and enough for reduction; (4) $\mathrm{P}_{1}$ e $\mathrm{P}_{2}$ are physics attributes and (3c) is a physics law. The laws $(3 \mathrm{a}, \mathrm{b})$ are named bridge-laws between certain laws ('proper') of (1) and (3c) types. Such laws connect their attributes of the special sciences with the attributes of the theories to which they reduce themselves. Thus, any antecedent or consequent formula in relation to a certain law must appear as a reduced formula in bridge-laws.

According to Fodor, the point to be discussed is the connector's nature ' $\rightarrow$ '. He affirms that if this is understood as "cause", so there may be other connectives for the bridge-laws, because the relation between (1) and (3c) is, actually, asymmetric, while the bridge-law connector ' $\Leftrightarrow$ ' expresses

8. Fodor has a special meaning for the term 'reduction': the expression 'reduce itself to' names a relation between the Physics science theories and the special science theory: "When a relation between a pair of theories is established, for example $\mathrm{T}_{0}$ e $\mathrm{T}_{1}$ it is said that $\mathrm{T}_{0}$ sub judges $\mathrm{T}_{1}$. The reduction relation is transitive and asymmetric, eventually unreflective”. (Fodor 1981: 149). The idea that Psychology reduces itself to Physics - the physicalist reductionism - does not cause the science union, but it is caused by this union. 
symmetric relations. This is a problem for the ontological tendency of the reductionist program: $\mathrm{S}$ and $\mathrm{P}$ must (it is nomologically necessary) be applied to the same things. Fodor argues that this is compatible to nonphysicalist ontology, linked more to properties rather than substances, that means, psychological and physical attributes apply themselves to organisms, but that does not mean that an event which satisfies a psychological attribute is a physical event, for example. The result is a sort of psychophysical dualism, of a non-Cartesian variety, that does not guarantee the physical generality.

However, if the bridge-laws expressed identity of contingent events, such as "every event that consists of the $\mathrm{x}$ of $\mathrm{S}_{1}$ satisfaction is similar to an event that consists of the $\mathrm{x}$ of $\mathrm{P}_{1}$ satisfaction and vice-versa", there would be the guarantee that every event that fits into a scientific law is a physical event. The ontological tendency to reductionism is thus clear and the generality of what is physical is guaranteed before the special sciences. From this it is possible to see the point of what Fodor calls token-physicalism: "token physicalism is simply the claim that all the events that the sciences talk about are physical events." (Fodor 1991: 130). About token physicalism, Fodor observes that: (i) it is weaker than materialism; (ii) it is weaker than the type-physicalism; and (iii) it is weaker than reductionism.

According to Fodor (1994a), materialism, in general, covers approaches such as radical behaviorism, logical behaviorism and the theory of the central state identity. In agreement with Fodor, each one of them presents some problems. Radical behaviorism simply rejects mental causes to explain behaviors. Logical behaviorism, recognizing the existence of mental states, defends a semantic theory in which the attribution of a mental state to an organism is the same as saying there is an availability for a specific behavior under certain conditions, then, having a sort of translation from the mental language to a language of responses and stimuli.

Identity Theory states that the property of being in a mental state is identical to the property of being in a neural physiological state; thus, it is not a semantic thesis. Identity Theory is expressed as a token-physicalism or as a type-physicalism. In the first case, every specific mental process that exists is neural physiological; in the latter, every specific mental process that could exist would be neural physiological, in the sense that "[...] token physicalism is weaker than what might be called 'type-physicalism', the 
doctrine, roughly, that every property mentioned in the laws of any science is a physical property" (Fodor 1981:130). In other words, it is the idea that the psychological types are identical to the neurological types. That would be the case if primitive syntactic expressions of the mentalese required its own homogeneity under a neurological description. (Fodor 1994a)

Fodor (1994a) arguments that the type-physicalism problem is that it excludes the possibility of other data processing systems that are not neural, such as human beings', since it focuses on the physical constituents of the system (or hardware). In this sense, he concludes that Identity Theory scientists move a little further on the causing matter of the mind-body relation; while the logical behaviorists move a little further on the relational character of the mental properties. Token-physicalism is conceived in the following way: every psychological event is a neurological event.

Reductionism is the conjunction of token physicalism with the assumption that "there are natural kind predicates in an ideally completed physics which correspond to each natural kind predicate in any ideally completed science." (Fodor 1981:131). It deals with a sufficient condition only for the token physicalism, and both cause the physical generality, considered as the only basic science.

In this sense, the reduction of the psychological process into a neurological one demands that any event of a psychological property must be identical to an event of a neurological property. That means, the psychological reductionist formulation is something as follows: all psychological natural type is (or is co-extensive with) a neurological natural type. This co-extensiveness should be nomologically necessary, in other words, the generalization which establishes this co-extension is a law ("bridge-laws are laws").

Fodor $(1981: 135,136)$ defends a psychological reductionism that does not affect the ontology of psychology. In his words:

[...] the reductionist program in psychology is clearly not to be defended on ontological grounds. Even if (token) psychological events are (token) neurological events, it does not follow that the kind predicates of psychology are coextensive with the kind predicates of any other discipline (including physics). That is, the assumption that every psychological event is a physical event does not guarantee that physics (or, a fortiori, any other discipline more general than psychology) can provide an appropriate vocabulary for psychological theories. 
Fodor (1981: 137) considers that psychological reductionism is not equivalent to token physicalism, but if there was such equivalence, it should be established through a psycho-physical type-to-type correlation. The problem, as the author warns, is that "every psychological event is paired with some neurological event or other, but psychological events of the same kind are sometimes paired with neurological events of different kinds". In token physicalism, the empirical confirmation depends on showing that the neurological counterparts of psychological events are identical to the properties which determine what kind of psychological event a certain event is.

Reductionism must explain the physical mechanisms in a way that the events agree with the special science laws. That leads us to preserve science unity. Fodor supports that, to preserve science unity (in a reviewed approach), it is necessary that "every Law of the special sciences should be reducible to physics by bridge statements which express true empirical generalizations." (Fodor 1981: 139). The correspondence between the reduced science and reducing science type-predicates is not required. The bridge-assertions express identities of token-events. The point is that both entities can differ in their physical structure, but, despite that, they can converge into many of their properties.

On the other hand, if the causing laws of the special sciences and the ones of the basic sciences have in common the licensing of attributions of causal responsibility (even existing metaphysical differences between the laws), they differ in certain aspects. In terms of causal responsibility, it is important to take into consideration that the truth of a law antecedent nomologically needs the truth of its respective consequent. Thus, Fodor (1990) highlights that the difference between the basic and special laws is that the first ones need a mechanism which guarantees that its antecedent's satisfaction leads to its respective consequent's satisfaction.

For him, the mechanisms which implement the intentional laws are computational or, more specifically, syntactic - syntax must be understood as a secondary physical property, an abstract trait of the symbol shape. $\mathrm{He}$ argues that:

Computers shows us how to connect semantical with causal properties for symbols [...] You connect the causal properties of a symbol with its semantics properties via its syntax. The syntax of a symbol is one of the higher-order physical properties. 
To a metaphorical first approximation, we can think of the syntactic structure of a symbol as an abstract feature of its shape. Because [...] syntax reduces to shape, and because the shape of a symbol is a potential determinant of its causal role, it is fairly easy to see how there could be environments in which the causal role of a symbol correlates with its syntax. (Fodor 1990: 22; 1987: 18-19).

Fodor admits the psychological laws are not basic; and the non-basic laws, which are the case of the intentional laws, need mediating mechanisms (unlike the basic laws). This way, a certain law can have different implementations. The clauses ceteris paribus quantify on this mechanism. So, it would be something as: 'As cause Bs ceteris paribus' means 'There is an intervening mechanism to mediate so that, when intact, $A$ s cause $B$ s'.

The next question is whether the intervening mechanisms are physical or not. Fodor, aptly, affirms that if the mental causes are not physical, the mediating mechanisms are physical. 'Physical mechanism' must be understood as the operation means covered by articulated laws in Physics. He considers there is a series of levels of laws and intermediate mechanisms, even though physical mechanisms implement laws of a higher level, that is: "[...] intentional laws that are implemented by neurological mechanisms that are governed by neurological laws that are implemented by biochemical mechanisms that [...] and so on down to physics." (Fodor 1990: 159, n.17).

The point is that computers manipulate symbols, and computation is a causal chain of states, an operation of formulas semantically interpreted in the machine code.

The semantic properties of a symbolic / mental representation are determined by aspects of its functional role, in causal terms. Fodor considers there are at least three types of causal relations to be used to fix the semantic properties of the mental representations: (i) causal relations between mental states and stimuli: beliefs as stimulation effect; (ii) causal relations between mental states and response: beliefs as behavior effect; (iii) causal relations between mental states and other mental states: beliefs as cause or effect of other beliefs.

According to Fodor (1994a), the idea that the semantic properties of the mental representations are determined by its functional role is central 
in Cognitive Science, although it is not known yet how these functional roles determine such semantic properties.

Fodor (1994a; 1994b:8) posits that the intentional laws are implemented by computational mechanisms. This implementing way differs from several other secondary physicalisms that, in a classic materialistic perspective, defend a biological implementation. He states: "Computational processes are those defined over syntactically structured objects; viewed in extension, computations are mappings from symbols to symbols; viewed in intension, they are mappings from symbols under syntactic description to symbols under syntactic descriptions." (Fodor 1994b: 8)

One of the problematic questions to be highlighted is the way the computational processes can cover the causal relations between the symbols and the world: "How could a process which, like computation, merely transforms one symbol into another guarantee the causal relations between symbols and the world upon which [...] the meanings of symbols depend?" (Fodor 1994b: 12-13). In other words, how to guarantee that a computational-syntactic operation casually connects tokens with the tokens of the property they correspond to? Besides, in order to have the computational implementation of intentional laws, there must be (a) enough computational conditions to satisfy the intentional properties; and (b) enough intentional conditions to satisfy the computational properties.

Consider that the syntactic structure is defined in the system internal level: "If an object (a thought, a sentence or whatever) has a syntactic structure at all, then what syntactic structure it has, is fixed given just its internal relations; i. e., given its relations to its parts." (Fodor 1994b: 14). So, it is about a relation between the internal states.

In this sense, the transition mechanism of mental states has a computational nature. If the psychological theories have ontological commitments from the way the mental states and processes are approached, so "[...] the computational account of mental processes would appear to be ineliminably committed to mental representations construed as structured objects." (Fodor 1987: 146-147).

Generally, reductionism and naturalistic restriction can follow the path of unintentional language to semantics, which leads to a classic computational model, ruled by syntax and following the principle of 
causal supervenience. Another way is naturalization of neural simulations (computational connectionist), somehow in a reductionist sense. The naturalization is still valid, super structurally. According to Lakoff \& Johnson (1999: 15):

Cognitive science - the empirical study of the mind - calls upon us to create a new, empirically responsible philosophy, a philosophy consistent with empirical discoveries about the nature of the mind. This is not just old-fashioned philosophy "naturalized" - making minor adjustments, but basically keeping the old philosophical superstructure.

Recovering textually (from section 3) the proposal of the Language Neural Theory, we find in first place the description of the paradigm levels:

(I)

Level 1: Cognitive Science and Cognitive Linguistics

Level 2: Neural Reducible Conventional Computational Models

Level 3: Structured Connectionist Model

Level 4: Computational Neuroscience

Level 5: Neuroscience

In second place, the following quotations:

(II) Such conventional computational mechanisms are only used when it is known how to map them directly to structured connectionist neural models, and it is common for novel forms of conventional-style models to be constructed along these guidelines. Thus, only neutrally reducible computational models are used in the modeling (Lakoff \& Johnson 1999: 571)

(III) No ontological relevance is ascribed to the level of conventional computations. It is there purely for convenience, to make the job of neural modeling easier. The neural computations attributed to the brain are characterized on Level 3, the structured connectionist level. These must be equivalent to the neural computations carried out by the more complex brain circuitry on level 4, which more directly models the details of the physical (Lakoff \& Johnson 1999: $571,572)$.

In the excerpts I, II and III, according to the passages in bold, we find the idea that the Language Neural Theory, in order to do interdisciplinary research, chooses some "kind of" reduction. In level 2, in accordance with III, the conventional computations have no ontological (or metaphysical) intentions, having then just an operational value. However, this operational 
value (of convenience) acquires a strategic methodological role in the transition from Level 1 until Level 5, this one is the level in which embodiment is no longer strictly phenomenological, in our point of view. It is not probably about a token physicalism, but a type physicalism, since the previous level "needs to be", even though strategically, computational.

So, to keep the explanation in ontological terms, the proposed metatheory (being reductionist) must not take the conventional computations as a level. It should be absorbed by Level III as one of the "problems" to be struggled by structured connectionism.

This is an appropriate context to ask some questions, such as: There would be another alternative for the Language Neural Theory, which is not in agreement with the common reductionist theory? How the relation with the five levels could happen? There is a suggested alternative in the conclusion section of this article.

\section{Conclusion}

Rohrer (2001: 62) states that: "the scope of the embodiment hypothesis requires thinking through evidence drawn from a multiplicity of perspectives on embodiment, and from multiple methodologies". Rohrer comes up with ten different embodiment conceptions and identifies some researches that operate with one or more conceptions simultaneously. ${ }^{9}$ His position is that,

Of particular interest of course, are research projects that build bridges or perform parallel experiments across these differing dimensions. It is my contention that much of the confusion stemming from this situation of multiple overlapping dimensions of the term 'embodiment' might be alleviated if research in cognitive linguistics were conceived in a broad-based theoretic framework.

The Language Neural Theory, obviously, is conceived in wider theoretical thought and, because of this, it promotes an overlapping between embodiment conceptions, considering the five levels - (1)

9. The different embodiment conceptions characterized by Rohrer (2001) are not presented here due to lack of room for a discussion about it in details. However, it can be affirmed the Language Neural Theory operates with more than one conception. 
Cognitive Science and Cognitive Linguistics, (2) Neural Reducible Conventional Computational Models, (3) Structured Connectionist Model, (4) Computational Neuroscience and (5) Neuroscience - in which the paradigm intends to operate. The overlapping degree may be problematic, depending on a more detailed and demonstrative discussion.

The theory aims to cover embodiment in these five levels, weakening its experiential-phenomenological aspect, until it reaches a proper "physiologic" level. At the lowest level, it is extremely important to examine experientially how bodies effectively work in an anatomic, neural-functional and neuralbiological level. Besides, even as a "strategic" paradigm, if the transition from the cognitive level to the neural-biological one is a gigantic step, as Lakoff \& Johnson (1999) affirm, and probably due to what it demands in terms of empirical research, the computational levels are a methodological step with risked and, as far as it is known about the state-of-the-art in Cognitive Science, compromised movements with controversial not merely technical, but also of non-trivial episteme methodological nature.

For example, a challenge is presented by Edelman \& Tononi (2000: 47). According to them, the studies on neural anatomy and neural dynamics

indicate that the brain has special features of organization and functioning that do not seen consistent with the idea that it follows a set of precise instructions or performs computations. [...] If we ask whether the connections are identical in any two brains of the same size, as they would be in computers of the same make, the answer is no. [...] Although the overall pattern of connections of a given brain area is describable in general terms, the microscopic variability of the brain at the finest ramifications of its neurons is enormous, and this variability makes each brain significantly unique. These observations present a fundamental challenge to models of the brain that are based on instructions or computation.

Authors remind that today no machine is able to embody this individual diversity as the central aspect of its design, "although the day will certainly come when we shall build devices that are truly brainlike." (Edelman \& Tononi 2000: 47)

On the other hand, for example, to evidence the existing polemics, while dealing with neural biological and computer models, Spitzer (1999) arguments against network models, which are said to be acceptable only in engineering, not in neuroscience. Spitzer defends network simulations, 
whenever they show similarities with biological observations, they acquire relative plausibility and great application value in determined areas (among them, mental disorders in psychiatry, as the author emphasizes). Certain network models are abstract by nature and analogue to biological structures only in certain aspects.

The debate is full of complex questions on philosophy of the mind - and still open - and full of examples for and against computational modeling to the brain (or electronic brain). This debate is based on a varied series of "verifications" and empirical data, from the use of new technologies concerning anatomic and functional "scanning" of the brain (fMRI, PET, etc.), besides experiments that use a wide range of instruments.

Our point of view is that embodiment demands a meta-theorization for itself. We assume that embodiment, as an investigation phenomenon, should not be formulated in terms of levels, being treated as interfaces instead, at such manner that: (a) the epistemological commitments should be synchronically sustained in all interfaces of the investigation paradigm; (b) the conventional computational level couldn't be sustained as one of the paradigm "levels", but, rather, as one of the problems which has to be treated in the structured connectionism plan; (c) the strategic reduction levels paradigm and the results obtained from it might imply a kind of modularization of the program of research itself; and (d) the modules would be interdependent only as a result of the reductionist proposal. As a result, I assume that it is possible to do Cognitive Linguistics without adhering to structured connectionism, or to neurocomputacional simulation, as long as one would operate with interfaces constructions between domains of investigation, and not with a reductionist features paradigm treated in terms of "interfaces".

That means it is plausible and enjoyable to work with Cognitive Linguistics without necessarily accepting structured connectionism, or more specifically, the neural-computational simulation. In this proposed paradigm level, complex problems of Cognitive Science are found and there is no approach consistent enough in the phenomena description or explanation. Besides, the paradigm still suggests a lot of meta-theoretical discussions, especially about ontological commitments and implications to use investigative methods. We need to wait for a reductionist project in Cognitive Linguistics to keep its research program open to boundary 
investigations - or constitutive - such as the ones about how discourse works at its wide historical, social, cultural, ideological, literary aspects and many others.

Would there be another alternative which is not reductionist for this paradigm? An option is the level interface without ontological reductions "top down"; that means the intra and interdisciplinary interfaces or the ones between theoretical and experiential domains would not implicate equivalences/ translations between entities, but they would allow continuing check-ups about the theoretical consequences between the domains, empirical-experiential fundamentals and repercussions in the application field. No meta-theoretical ontological commitment would accept a priori as a dialog condition between the paradigm levels as a whole. The ontological building would be at a dialog service for each interface, so that the ontological correspondence did not become an intrinsic restriction to the paradigm as a whole. Thus, instead of operating with a Reduction Theory, it would work with an Interface Theory, which would protect each paradigm level from innovating hypothesis. According to Campos \& Feltes (2009), an Interface Theory is still a non-reductionist trans-disciplinary project, but the details of this subject demand more discussion.

Recebido em dezembro de 2009 Aprovado em dezembro de 2009

E-mail: helocogn@terra.com.br

\section{REFERENCES}

Campos, Jorge \& Heloísa Pedroso de Moraes Feltes. 2009. Filosofia da linguística, filosofia da ciência e os pressupostos para a construção de uma metateoria das interfaces. Seminários de Estudos Linguísticos, Ceará: Universidade Federal do Ceará, (in press), 18p.

Edelman, Gerald M. \& Giulio TonOni. 2000. A universe of consciousness: how matter becomes imagination. New York: Basic Books.

Feldman, Jerome A. 2006. From molecule to metaphor: a neural theory of language. Cambridge, Mass.: A Bradford Book; The MIT Press.

Feltes, Heloísa Pedroso de Moraes. 1998. Naturalização da semântica das representações mentais: o programa de pesquisa de Jerry A. Fodor. Tese (Doutorado), Pontifícia Universidade Católica do Rio Grande do Sul, Porto Alegre, 262 p. 
Fodor, Jerry A. 1981. Representations: philosophical essays on the foundations of cognitive science. Cambridge, Mass.: A Bradford Book; The MIT Press. 1987. Psychosemantics: the problem of meaning in the philosophy of mind. Cambridge, Mass.: A Bradford Book; The MIT Press. . 1990. A theory of content and other essays. Cambridge, Mass.: A Bradford Book; The MIT Press. 1994a The mind-body problem. In: Richard Warner \& Tadeusz Szubka. The mind-body problem: a guide to the current debate. Cambridge, Mass.: Blackwell, 24-40. . 1994b. The elm and the expert: mentalese and its semantics. Cambridge, Mass.: A Bradford Book; The MIT Press.

Fodor, Jerry. A. \& E. Lepore. 1994. Why meaning (probably) isn't conceptual role. In: S. P. STich \& Ted A. Warfield (eds.) Mental representation: a reader. London: Blackwell Publ., 142-156.

Fodor, Jerry \& Brian McLaughlin. 1990. Connectionism and the problem of sistematicity. Why Smolensky's solution doesn't work. Cognition, 35, 183-204,

Fodor, Jerry A. \& Zenon Pylyshyn. 1988. Connectionism and cognitive architecture: a critical analysis. Cognition, 28, 3- 71.

VAN GELDER, Tin. 1990. Compositionality: a connectionist variation on a classical theme. Cognitive Science, 14, n. 3, 355 - 384, jul./sep.

JoHnson, Mark. 1988. The body in the mind: the bodily basis of reason and imagination. Chicago: University of Chicago Press.

LAKOFF, George. 1977. Linguistics gestalts.. Papers from the Thirteenth Regional Meeting, Chicago Linguistics Society, 13, 236-287.

.1982 Experiential factors in linguistics. . In: T. SimON; R. ScHOLES (eds.). Language, mind, and brain. Hillsdale, N. J.: Lawrence Erlbaum, 142-157.

. 1987. Women, fire, and dangerous things: what categories reveal about the mind. Chicago: The University of Chicago Press.

. 1988. Cognitive semantics. 1988 U. Eco; M. Santambrogio \& P. Violi (eds.) Meaning and mental representations. Indianapolis: Indiana University Press, 119-154.

Lakoff, George \& Mark Johnson. 1980. Metaphors we live by. Chicago: University of Chicago Press.

1999. Philosophy in the flesh: the embodied mind and its challenge to Western thought. New York: Basic Books. 
LANGACKER, Ronald. 1999. Assessing the cognitive linguistic enterprise. In:, Theo Janssen \& Gisela Redeker (eds.) Cognitive Linguistics: foundations, scope, and methodology. New York: Mounton de Gruyter, 13-59.

LyCAN, William. 1990. Introduction. In: William Lycan (ed.). Mind and cognition: a reader. London: Basil Blackwell Publ., 3-13.

McLaughlin, Brian P. 1993. The connectionism/classicism battle to win souls. Philosophical Studies, 71, n. 2, 163-190, Aug.

Merleau-Ponty, Maurice. [1945] 1999. Fenomenologia da percepçãa. 2. ed., São Paulo: Martins Fontes.

Place, U. T. 1990. Is consciousness a brain process? In: William Lycan (ed.). Mind and cognition: a reader. London: Blackwell Publ., 29-36.

Pylyshyn, Zenon W. 1986. Computation and cognition: toward a foundation for cognitive science. Cambridge, Mass.: MIT Press.

Rohrer, Tim. 2001. Pragmatism, ideology and embodiment: William James and the philosophical foundations of cognitive linguistics. In: Sandriklogou \& R. Dirven (eds.) Language and ideology: cognitive theoretical approaches. Amsterdam: John Benjamins, 49-82.

SMOLENSKY, P. 1988. On the proper treatment of connectionism. Behavioral and Brain Sciences, n. 11, 1-23.

SpITzer, Manfred. 1999. The mind within the net: models of learning, thinking, and acting. Cambridge, Mass.: The MIT Press.

Tye, Michael. 1992. Naturalism and the mental. Mind, 101, n. 403, 421-441, jul.

W Arfield, Ted A. \& Stich, Stephen. 1994. Introduction. In: S. P. Stich \& Ted A. Warfield (eds.) Mental representation: a reader. London: Blackwell Publ., 3-8.

Watson, J. B. 1990. An excerpt from Talking and Thinking. In: William Lycan (ed.). Mind and cognition: a reader. London: Blackwell Publ., $14-22$. 